\title{
Assessing the hedging potential of gold and other precious metals against uncertainty due to epidemics and pandemics
}

\author{
Abdulsalam Abidemi Sikiru ${ }^{1,2}$. Afees A. Salisu ${ }^{3}$ \\ Accepted: 25 July 2021 / Published online: 6 August 2021 \\ (C) The Author(s), under exclusive licence to Springer Nature B.V. 2021
}

\begin{abstract}
We assess the hedging capabilities of four prominent precious metals namely gold, palladium, platinum and silver against market risks due to epidemics and pandemics. The research objective is informed by the COVID-19 pandemic which amplifies health risks with attendant concerns for financial markets. We utilize the health-related uncertainty index developed by Baker et al. (Equity market volatility: infectious disease tracker [INFECTDISEMVTRACK], 2020) which measures uncertainty in the financial markets due to infectious diseases including the COVID-19 pandemic and construct a predictive model that accommodates the salient features of both the predictand and predictor series. Our results support the safe haven property only for gold before and during the COVID-19 pandemic. We push the analysis further for in-sample and out-of-sample forecast evaluation and find that accounting for uncertainty due to infectious diseases improves the forecast of the four precious metals relative to the benchmark model (historical average). We highlight for investors that the gold market remains the safest market among the precious metals particularly during the COVID-19 pandemic.
\end{abstract}

Keywords Epidemics $\cdot$ Pandemics $\cdot$ Precious metals $\cdot$ Hedging $\cdot$ Forecast evaluation

JEL Classification I19 · G11 · D81

Afees A. Salisu

adebare1@yahoo.com

Abdulsalam Abidemi Sikiru

abdulsal20022001@yahoo.com

1 Research and Statistics Department, West African Monetary Agency, Freetown, Sierra Leone

2 Monetary Policy Department, Central Bank of Nigeria, Abuja, Nigeria

3 Centre for Econometric and Allied Research, University of Ibadan, Ibadan, Nigeria 


\section{Introduction}

This study pursues two objectives. The main objective addresses the hedging potentials of gold, in its special class, ${ }^{1}$ along with other precious metals including palladium, silver and platinum, in the face of contemporary market risks traced to epidemics and pandemics. The auxiliary research objective complements the main objective by assessing the predictive content of information contained in health risk (using the Equity Market VolatilityInfectious Disease - EMV-ID dataset as a proxy) for precious metals returns. With the focus on health risks due to epidemics and pandemics and the broad analysis of precious metals, we are able to extend the existing literature (Gozgor and Ongan 2017; Otero and Reboredo 2018; Raza et al. 2018; Qadan 2019) that are only limited to the resilience of gold returns to various measures of uncertainties. In essence, the previous studies ignore the current health-induced market threat in the predictability of analysis of precious metals. With this effort, we are able to offer valuable guide to investors on assets to hold in their portfolios during periods of high market uncertainty, as experienced during the COVID19 pandemic. The only exception, to the best our knowledge, is the work of Salisu et al. (2021) which also assesses the predictability of markets for precious metals covering also the COVID-19 pandemic. We however differ in terms of the measure of the uncertainty index/market risks. While Salisu et al. (2021) lean more towards financial risk as contained in the stock market volatility index (Chicago Board Options Exchange (CBOE)), our study leans more towards health risk using the health-related uncertainty index developed by Baker et al. (2020) which measures uncertainty in the financial markets due to infectious diseases including the COVID-19 pandemic. The Baker et al. (2020) uncertainty index christened as Equity Market Volatility Infectious Diseases is currently gaining momentum in the financial economics literature as a good proxy for the analysis of uncertainty associated with epidemics and pandemics including COVID-19 pandemic (see Salisu and Sikiru 2020; Salisu and Adediran 2020; Salisu et al. 2020b; Adediran et al. 2021).

The need for this study is justified for investment benefits obtained from the findings based on the ability of the precious metals to provide cover for investors by hedging against health risk as exemplified during the early period the COVID-19 pandemic (Akhtaruzzaman et al. 2020; Ji et al. 2020). ${ }^{2}$ The theoretical construction for tying the hedging role to the precious metals can be traced to Baur and Lucey (2010) with the argument that the potential safe asset would be able to compensate investors for losses not only on the average but specifically during market stress when the prices of other traditional assets crash. Hence, investors would be offered the opportunity to seek succour in the safe assets if they could provide hedging role against the prevailing market risk for which stocks, equities, and bonds suffer severe losses (see Baur and Lucey 2009, 2010; O'Connor et al. 2015).

Our study concludes that only gold consistently exhibits safe haven potential against uncertainty, thereby indicating that gold is the only precious metal able to hedge market risks due to epidemics and pandemics. This aligns with the literature analysing the safe

\footnotetext{
1 The special interest in gold is not misplaced. In the class of precious metals (including silver, palladium and platinum) with inherent store of value properties, gold is widely regarded as the dominant safe asset against risks and uncertainties (see Starr and Tran 2008; Agyei-ampomah et al. 2014; Lucey and Li 2015; Vigne et al. 2017; Huynh 2020; Salisu et al. 2020a, b, c).

2 Corbet et al. (2020a) argued that the COVID-19 pandemic contributed to financial market confusion that increased the need for the search for safe havens. Further, Corbet et al. (2020b) document that the cryptocurrency market was significantly affected by the negative sentiments occasioned by the COVID-19 pandemic.
} 
haven potential of precious metals against other market risks (see for example, Baur and Lucey 2010; Bredin et al. 2015; Bialkowski et al. 2015; Areal et al. 2015; Huynh and Burggraf 2019; Ji et al. 2020; Akhtaruzzaman et al. 2020). Unlike Salisu et al. (2021) which show that precious metals can hedge financial risks, we uphold that only gold possess this quality for health risk. Thus, precious metals may respond differently to risk factors and therefore generalizing with the finding of Salisu et al. (2021) may be misleading. This is a major contribution of our research findings to the literature. An extension that accommodates the economic significance of our predictability results would be more insightful particularly to profit maximizing investors seeking to minimize risks during epidemics and pandemics.

Following the introduction section, Sect. 2 offers a succinct review of the literature on the subject. Section 3 deals with data issues and the methodology for assessing the hedging role of precious metals as well as the predictability of the health-related uncertainty index. Section 4 presents results and discussion and Sect. 5 concludes the paper.

\section{Literature review}

The theoretical construction for tying a hedging role to an asset in extreme situations can be traced to Baur and Lucey (2010). This asset is considered a safe haven that is not only negatively correlated with traditional assets/portfolio on the average, but also exhibits this feature in times of market crises/extreme market situations. The implication of this is that such a safe asset/portfolio is able to compensate investors for losses incurred when the prices of other assets crash. Hence, in our specific example, the theoretical attractiveness of gold and the other precious metals lies in their abilities to show resilience in times of market stress like the example of the financial stress in the COVID-19 period (see O'Connor et al. 2015). ${ }^{3}$ This falls under the flight-to-quality idea, which suggests that investors could find it smart to run from equities, bonds and other traditional assets to precious metals should there be severe losses in former markets (see Baur and Lucey 2009, 2010). In essence, the precious metals would function as safe assets to hedge against market risks should they be able to aid investors in building expanded portfolio that help reduce downside risk (see $\mathrm{Ji}$ et al. 2020).

The empirical literature is dominated by research on gold and this is not far-fetched. O'Connor et al. (2015) provide excellent and extensive review regarding gold as a financial instrument and strategic commodity with historical discussions. In addition to the present-day discussions around gold as a financial instrument, the authors (O'Connor et al. 2015) traced the long history of gold as a store of wealth or as a monetary standard up to $3000 \mathrm{BC}$ among the Sumerians, about 2500BC in Ur of Chaldeas and 1400BC in Egypt. Due to its long time reputation among financial investors as a store of value to safeguard investment (see Baur and Lucey 2010; Beckmann et al. 2018; Qadan 2019), gold differs from the other precious metals

\footnotetext{
3 A plethora of studies have established strong correlations between the current pandemic and financial assets with the outcome suggesting the need for hedging to minimize the adverse effect of the former on the latter. Examples of these studies include those on stock market (see Gil-Alana and Claudio-Quiroga 2020; Salisu and Vo 2020; Salisu et al. 2020a, b, c; Liu et al. 2020; Salisu and Akanni 2020; Salisu and Sikiru 2020; Sharma 2020), foreign exchange market (see Narayan 2020a, b; Narayan et al. 2020), and crypto currencies (Conlon and McGee 2020; Corbet et al. 2020a).
} 
as they are more considered for industrial uses in the production of jewelleries, alloys, catalysts, solar panels, among others (see Batten et al. 2010; O'Connor et al. 2015).

The relevant empirical evidences can be divided into: one, those that examine whether the assets have negative correlation with traditional assets on the average, in which case, the underlying asset (precious metals in our specific case) can serve as hedges for stocks and bonds; two, the group of studies that search for safe havens, that is, assets that are able to deliver consistent positive returns when other markets are in crisis. One of the major defining papers in the area of study, Baur and Lucey (2010) find that gold can act as both hedge and safe haven for stocks during market crisis, but the latter property is only transient. Bredin et al. (2015) show that gold could provide safety against financial risks in the stock market in the long run (see also Areal et al. 2015). A similar but with different findings obtained from Bredin et al. (2017) reveal that precious metals could help mitigate downside risk only at short horizons.

A number of studies that have shown that gold price/returns remain positive (that is, gold retains its safe asset property) in the face of rising uncertainties such as economic policy uncertainty (see for example, Balcilar et al. 2016; Jones and Sackley 2016; Li and Lucey 2017; Beckmann et al. 2018; Bilgin et al. 2018; Chai et al. 2019), financial markets uncertainties (see for example, Baur and McDermott 2010; Bialkowski et al. 2015; Gao and Zhang 2016; Peng 2019), inflation risks (see for example, Jain and Ghosh 2013; Batten et al. 2014; Beckmann et al. 2015; Lucey et al. 2017; Conlon et al. 2018), currency risks (see for example, Reboredo and Rivera-Castro 2014; Qureshi et al. 2018), and geo-political risks (see for example, Hou et al. 2017; Huynh and Burggraf 2019; Burggraf et al. 2019; Qin et al. 2020).

On studies relating to the COVID-19 pandemic, while Ji et al. (2020) find that gold could offer safety for equity market investors during the pandemic (01/12/2019 to 31/03/2020), Bouri et al. (2020) conclude find that the role of gold as a safe asset during the pandemic is not superior to Bitcoin. Akhtaruzzaman et al. (2020) document that gold can serve as a hedge for different stock indices (S\&P500, Nikkei 225, China FTSE A50, and Euro Stoxx 50) during the first phase of the pandemic (31/12/2019-16/3/2020) but lost the prowess in the second stage (17/3/2020-24/04/2020). Similar results from Adediran et al. (2021) show that the powers of the prospective "safe" asset classes became weakened during the pandemic with only gold, silver, Bitcoin and commodity futures retaining some hedging roles against risks posed during the pandemic. A strikingly similar study by Ji et al. (2020) shows that gold, foreign exchange, commodities and cryptocurrency become less effective in hedging market risk during the pandemic. Also similarly, Salisu and Sikiru (2020) employ the Economic Policy Uncertainty dataset to show evidence of hedging powers for Asia-Pacific Islamic stocks and this feature also declined during the pandemic.

The study on which the present study builds its contribution, Salisu et al. (2021) show that gold retains its safe haven properties but dwindled during the pandemic. However, unlike the work of Salisu et al. (2021) which is limited to financial risk, our study probes further by considering health risk measured by the equity market volatility-infectious disease tracker - EMV-ID dataset of Baker et al (2020). This consideration further strengthens the literature particularly in terms of the sensitivity of the precious metals to different market risks. 


\section{Methodology and data}

This study relies on a predictive model for precious metals returns on the basis of the measure of health risk (the epidemics and pandemics uncertainty index) as the predictor. The formulation of the empirical model here allows us to assess the hedging role of gold and other precious metals against market risks brought to fore by epidemics and pandemics including the COVID-19 pandemic. The formulation relies on Baur and Lucey (2010) such that investment in the precious metals' market will be expected to retain or increase in value during times of market turbulence (or high market volatility) like we experienced in the early period of the COVID-19 pandemic (Akhtaruzzaman et al. 2020; Ji et al. 2020). In this case, the precious metals would be expected to remain negatively correlated with equities and debts during turbulence (see also O'Connor et al. 2015). Since the impact of pandemics is usually global, we anticipate a positive correlation between a measure of uncertainty due to pandemics and returns on investment in the precious metals. In other words, as the uncertainty due to pandemics increases, investors are tempted to look elsewhere for safe investments and if truly precious metals possess safe haven property, they should be safe destination for investments during the pandemic and by extension the returns should improve as trading in the market improves.

Consequently, we construct a predictive $\operatorname{model}^{4}$ for the returns of each of the precious metals as a linear function of the predictor series, health risk, and control (macroeconomic) variables ${ }^{5}$ :

$$
r_{t}=\alpha+\beta z_{t-1}+\lambda_{a d j} h r_{t-1}+\gamma\left(h r_{t}-\rho h r_{t-1}\right)+\eta_{t}
$$

where $r_{t}$ is the log return of the respective precious metal prices; $h r_{t}$ is a measure of epidemics and pandemics using the EMV-ID of Baker et al. (2020); $z_{t}$ is a vector of control variables; the global oil price (Brent crude oil price) and foreign exchange rate (USD/ GBP) whose consideration is motivated by their influence on the global financial environment (see Dong and Yoon 2019; Narayan 2020c; Nguyen et al. 2021) and both are measured in log return form to circumvent unit root problem; $\eta_{t}$ is the regression error term; and the coefficient $\lambda^{a d j}=\lambda-\gamma\left(1-\rho_{0}\right)$ measures the relative impact of the uncertainty on the precious metals; $\rho$ is the persistence parameter of the main predictor series $\left(h r_{t}\right)$, $\gamma\left(h r_{t}-\rho_{0} h r_{t-1}\right)$ is included to correct for possible endogeneity bias resulting from the correlation between the main predictor and the error term; all the data are pre-weighted by $1 / \hat{\sigma}_{t}$, which is the inverse of the conditional standard deviation of disturbance term in order to take care of conditional heteroscedasticity effect in the model.

In evaluating the model, we supress the results of the evaluated $\beta$ 's, which are coefficients of control variables as a way of staying within the focus of the study. Notwithstanding, the full results covering all the predictors including the control variables are presented in the "Appendix". In order to evaluate the hedging role of the precious metals against epidemics and pandemics, we observe the behaviour of the $\lambda^{\text {adj }}$ coefficient. The respective precious metals would be said to hedge against the health risk if the coefficient is positive and statistically significant

\footnotetext{
4 The methodology adopted here is similar to that of Salisu, Raheem and Vo (2021) except that we use the new dataset that accommodates all the variants of pandemics and epidemics unlike the mentioned study which is limited to financial risk (using the CBOE VIX index).

5 The specification follows the Westerlund and Narayan $(2012,2015)$ by controlling for endogeneity bias, conditional heteroscedasticity effect and persistence, typical of most financial and economic time series with high frequency.
} 
Table 1 Summary statistics and residual based tests

\begin{tabular}{|c|c|c|c|c|c|c|}
\hline & \multicolumn{2}{|l|}{ Full } & \multicolumn{2}{|l|}{ Pre-COVID } & \multicolumn{2}{|l|}{ COVID } \\
\hline & Gold return & EMV-ID & Gold return & EMV-ID & Gold return & EMV-ID \\
\hline Mean & 0.0215 & 0.4224 & 0.0261 & 0.4318 & 0.0378 & 19.465 \\
\hline Std. dev. & 1.0503 & 1.0001 & 1.0433 & 1.0215 & 1.1883 & 12.646 \\
\hline \multicolumn{7}{|c|}{ Autocorrelation } \\
\hline $\mathrm{k}=2$ & $15.54 * * *$ & $173.97 * * *$ & $19.225 * * *$ & $163.16^{* * * *}$ & $4.741^{*}$ & $296.18 * * *$ \\
\hline $\mathrm{k}=4$ & $16.46^{* * * *}$ & $261.09 * * *$ & $20.754 * * *$ & $245.23 * * *$ & $8.339^{*}$ & $541.22 * * *$ \\
\hline $\mathrm{k}=6$ & $28.45 * * *$ & $331.62 * * *$ & $33.441 * * *$ & $310.35 * * *$ & $26.482 * * *$ & $759.93 * * *$ \\
\hline \multicolumn{7}{|c|}{ Heteroscedasticity } \\
\hline $\mathrm{k}=2$ & $114.85 * * *$ & 0.2293 & $125.71 * * *$ & 0.2068 & 1.309 & $123.47 * * *$ \\
\hline $\mathrm{k}=4$ & $83.78 * * *$ & 0.1275 & $91.24 * * *$ & 0.1141 & 0.832 & $78.53 * * *$ \\
\hline $\mathrm{k}=6$ & $68.28 * * *$ & 0.4203 & $75.15 * * *$ & 0.3872 & $6.562 * * *$ & $51.50 * *$ \\
\hline Obs. & 5930 & 5930 & 5600 & 5600 & 300 & 300 \\
\hline
\end{tabular}

EMV-ID is the Equity Market Volatility-Infectious Diseases; Std is the standard deviation. For autocorrelation and heteroscedasticity tests, the reported values are the Ljung-Box test Q-statistics for the former and the ARCH-LM test F-statistics in the case of the latter. We consider three different lag lengths (k) of 2, 4, and 6 for robustness. The null hypothesis for the autocorrelation test is that there is no serial correlation, while the null for the ARCH-LM (F distributed) test is that there is no conditional heteroscedasticity.

$*$, **, ***Imply the rejection of the null hypothesis in both cases at $1 \%, 5 \%, 10 \%$ levels of significance, respectively

(that is, $\lambda^{a d j}>0$ ), otherwise (when $\lambda^{\text {adj }}<0$ ), the asset is as vulnerable as the traditional assets in the face of market risks. The predictive power of the health risk as a predictor would be regarded as weak if $\lambda^{\text {adj }}=0$.

As depicted in Eq. (1), our analysis essentially involves three classes of variables namely, the precious metals returns (gold, platinum, silver and palladium), macroeconomic variables used as control (Brent crude oil price and USD/GBP foreign exchange rate) and the measure of health risk due to epidemics and pandemics $\left(h r_{t}\right)$ (the Equity Market Volatility-Infectious Diseases tracker - EMV-ID). The precious metals are obtained from Quandl database while the rest are retrieved from the Federal Reserve Bank of St. Louis. We utilize daily data over the period of 4/2/1990 and 3/31/2021 (including the COVID19 period) based on data availability of the precious metals prices particularly platinum and palladium. The analyses are conducted for the full sample (4/2/1990-3/31/2021) and the two sub-samples; pre-COVID (4/2/1990-12/23/2019) and COVID period (12/31/2019-3/31/2021). The sub-samples enable us to separate the COVID-19 pandemic from other epidemics and pandemics (such as the 2012 Middle East Respiratory Syndrome Coronavirus (MERS-CoV), 2009 H1N1 Pandemic (H1N1pdm09 virus), the 2014 Ebola Virus Disease (EVD) epidemic in West Africa, 2005 Avian Influenza (H5N1), among several others). 
Table 2 Results of unit root tests

\begin{tabular}{|c|c|c|c|c|c|c|c|}
\hline \multirow[t]{2}{*}{ Variable } & \multicolumn{3}{|l|}{ ADF test } & \multicolumn{3}{|l|}{ NL test } & \multirow[t]{2}{*}{ Break dates } \\
\hline & Level & FD & $\mathrm{I}(\mathrm{d})$ & Level & FD & $\mathrm{I}(\mathrm{d})$ & \\
\hline \multicolumn{8}{|l|}{ Full sample } \\
\hline Gold return & $-81.029 * * *$ & - & $\mathrm{I}(0)$ & $-88.802 * * *$ & - & $\mathrm{I}(0)$ & - \\
\hline EMV-ID & $-17.959 * * *$ & - & $\mathrm{I}(0)$ & $-462.57 * * *$ & - & $\mathrm{I}(0)$ & $\begin{array}{l}1997-09-22 \\
2004-06-03 \\
2009-02-25\end{array}$ \\
\hline \multicolumn{8}{|c|}{ Pre-COVID announcement } \\
\hline Gold return & $-79.331 * * *$ & & $\mathrm{I}(0)$ & $-85.597 * * *$ & - & $\mathrm{I}(0)$ & - \\
\hline EMV-ID & $-17.512^{* * * *}$ & & $\mathrm{I}(0)$ & $-5871.7 * * *$ & - & $\mathrm{I}(0)$ & $\begin{array}{l}1997-09-22 \\
2004-06-03 \\
2009-02-11\end{array}$ \\
\hline \multicolumn{8}{|c|}{ Post-COVID announcement } \\
\hline Gold return & $-15.488 * * *$ & - & $\mathrm{I}(0)$ & $-16.688 * * *$ & & $\mathrm{I}(0)$ & - \\
\hline EMV-ID & $-2.849^{*}$ & $-13.688 * * *$ & $\mathrm{I}(1)$ & $-7.425 * * *$ & & $\mathrm{I}(0)$ & $2020-05-21$ \\
\hline
\end{tabular}

EMV-ID is the Equity Market Volatility-Infectious Diseases; ADF test is the Augmented Dickey Fuller test; NL test is the Narayan and Liu (2015) test; FD denotes First Difference. The test regression for all the unit root tests includes intercept and trend; I(d) implies the order of integration, where $\mathrm{d}$ is the number of differencing required for a series to become stationary; EMV-ID is logged while the gold return is expressed in $\log$ return form. The breaks are determined using the Bai and Perron (2003) test

$*, * *, * * *$ Indicate the rejection of the null hypothesis of a unit root at $1 \%, 5 \%$ and $10 \%$, respectively

Table 3 Persistence and endogeneity test results for EMV-ID

\begin{tabular}{|c|c|c|c|c|c|c|}
\hline & \multicolumn{3}{|l|}{ Persistence } & \multicolumn{3}{|l|}{ Endogeneity } \\
\hline & Full sample & Pre-COVID & COVID & Full sample & Pre-COVID & COVID \\
\hline EMV-ID & $0.1428 * * *$ & $0.1419 * * *$ & $0.7395^{* * *}$ & $0.0283 * *$ & $0.0264^{*}$ & $-0.0244 * * *$ \\
\hline
\end{tabular}

EMV-ID is the equity market volatility-infectious diseases

$* * *, * *, *$ Imply statistical significance of coefficients at $1 \%, 5 \%$, and $10 \%$ levels, respectively

\section{Results and discussion}

\subsection{Preliminary analyses}

The results sections follow the orientation of the paper which highlight gold in the midst of other precious metals. Hence, the analysis of gold preoccupies the main analysis while those of silver, palladium and platinum feature in the secondary results. However, prior to the formal analysis, we present preliminary results as a precursor to the main results in this section. The preliminary analyses cover the descriptive statistics (see Table 1), the unit root tests for the time series properties of the series (see Table 2), and the persistence, serial correlation, conditional heteroscedasticity and endogeneity tests required to validate the predictive model (see Table 3). We detail results for the full sample (4/2/1990-3/31/2021) and the periods before (4/2/1990-12/23/2019) and during the COVID-19 pandemic $(12 / 31 / 2019-3 / 31 / 2021)$ in all the results tables. 
Table 4 Estimation (predictability) results

\begin{tabular}{llll}
\hline & Full sample & Pre-COVID & COVID \\
\hline$\lambda^{\text {adj }}$ & $0.0389^{* * *}(0.0053)[7.3710]$ & $0.1766^{* * *}(0.0461)[3.8348]$ & $0.0517^{* * *}(0.0061)[8.4583]$ \\
\hline
\end{tabular}

We present the predictability results for the EMV-ID only while the full results for the multivariate model are presented in the Appendix. Values in parentheses-() denote standard errors while those reported in square brackets-[] are for t-statistics

$* * *, * *, *$ Imply the rejection of the null hypothesis of no predictability at $1 \%, 5 \%, 10 \%$ levels of significance, respectively

Three key observations emanate from Table 1. One, the mean values of the uncertainty index due to epidemics and pandemics are unusually higher during COVID-19 pandemic (19.47) compared with the period of other epidemics and pandemics before it (0.43). This corroborates the observations of Adediran et al. (2021) which show higher values of the different measures of financial uncertainty during the first wave of the COVID-19 pandemic. There are also other corroborations in Baker et al. (2020) and Zhang et al. (2020) which show that pandemics raise financial markets volatility in proportions greater than previously witnessed such as during the Global Financial Crisis. Two, the gold market reveals higher mean returns during the COVID-19 pandemics (0.038) than the other pandemics before it (0.026) and the full sample period (0.021) (see supporting theoretical arguments in Qadan (2019) of positive nexus between risk aversion in the conventional financial markets and gold returns). Three, there are convincing evidences especially during the COVID-19 pandemic and full sample for the presence of serial correlation and conditional heteroscedasticity in both the regressor and regressand series. These are shown by the widespread statistical significance of the serial correlation and conditional heteroscedasticity tests.

In Table 2, the results show that the series are largely stationary, hence, non-stationarity may not be an issue in the estimation process. However, in connection with the evidences of autocorrelation and conditional heteroscedasticity previously established, the results in Table 3 suggest that while persistence may be a source of concern in the modelling, the evidence for endogeneity bias is also compelling. With these background, we proceed to the main results to assess the predictability of gold and other precious metals' returns with the new dataset for epidemics and pandemics taking into account the highlighted statistical features as in Westerlund and Narayan $(2012,2015)$.

\subsection{The main results}

Recall the evaluation criteria defined for the precious metals to serve as worthy hedge for health risks in the modelling section. Gold and the others would be able to provide cover against the risks associated with epidemics and pandemics if the coefficient is positive and statistically significant such that $\lambda^{a d j}>0$, or weak hedge if $\lambda^{a d j}=0$, and inability to hedge health risk if $\lambda^{\text {adj }}<0$. On the other hand, given that the auxiliary research objective of this study is concerned with the predictability of the precious metals' returns on the basis of the new index, it is also necessary to define the evaluation criteria for judging the predictability. In essence, the epidemics and pandemics index would predict precious metals' returns when $\lambda^{a d j} \neq 0$ and the predictive power can be compared with a baseline model (historical 
Table 5 Forecast evaluation using Clark and West (2007) test

\begin{tabular}{|c|c|c|c|}
\hline & \multirow[t]{2}{*}{ In-sample } & \multicolumn{2}{|l|}{ Out-of-sample } \\
\hline & & $\mathrm{h}=30$ & $h=60$ \\
\hline Full sample & $0.1624 * * *(0.0181)$ [8.9508] & $0.1625 * * *(0.0181)[8.9930]$ & $0.1622 * * *(0.0180)$ [9.0170] \\
\hline Pre-COVID & $0.1367 * * *(0.0182)$ [7.5279] & $0.1371 * * *(0.0181)[7.5817]$ & $0.1381 * * *(0.0180)$ [7.6729] \\
\hline Post-COVID & $0.6266 * *(0.3098)[2.0229]$ & $0.6473 * *(0.2919)[2.2177]$ & $0.6258 * *(0.2660)[2.3523]$ \\
\hline
\end{tabular}

The rejection (non-rejection) of the null hypothesis implies the superior (inferior) performance of the uncertainty-based model for gold or any other precious metal relative to the benchmark model. The null hypothesis of a zero coefficient is rejected if this statistic is greater than +1.282 (for a one sided 0.10 test) +1.645 (for a one sided 0.05 test) and +2.00 for 0.01 test (for a one sided 0.01 test) (see Clark and West 2007). Values in parentheses-() denote standard errors while those reported in square brackets- [] are for t-statistics

$* * *, * *, *$ Imply the rejection of the null hypothesis of equal forecast accuracy at $1 \%, 5 \%, 10 \%$ levels of significance, respectively

average model) using the Clark and West forecast criteria for the in-sample and out-ofsample forecast evaluations.

The results presented in Table 4 are used to evaluate the hedging role of gold due to the risks associated with the epidemics and pandemics. Note that for brevity, we isolate the predictability results for the uncertainty index while the entire results for the multivariate model are presented in the Appendix, Table 8. Based on the criteria earlier highlighted, the positive sign of the coefficients indicates that gold retains its safe haven properties during epidemics and pandemics. This is supported by the statistical significance of the coefficients across board. In all, it appears that the health risk uncertainty series turns out to be a good candidate having significant impact on gold returns, thereby suggesting that gold can provide shelter against the risks posed by infectious diseases. Comparatively, the results show that the significance of the connection between EMV-ID and gold returns is higher during the COVID-19 pandemic period than the periods of other epidemics and pandemics judging by the $t$ statistics and also accompanied with lower risk-return ratio and by extension higher return-risk ratio. Therefore, including gold in the diversified portfolio of financial assets is encouraged. This is expected to improve the risk-adjusted return performance for investors particularly during the COVID-19 pandemic.

With the demonstration of the ability of gold as a safe asset for investors in times of market turmoil linked with epidemics and pandemics, we make significant addition to the literature and thereby intimate investors that the protection offered by gold, as previously established against policy uncertainty, inflation and currency risks, among others (for example, Reboredo and Rivera-Castro 2014; Bialkowski et al. 2015; Beckmann et al. 2015, 2018; Balcilar et al. 2016; Gao and Zhang 2016; Jones and Sackley 2016; Lucey et al. 2017; Li and Lucey 2017; Bilgin et al. 2018; Conlon et al. 2018; Qureshi et al. 2018; Chai et al. 2019; Peng 2019), can be extended to situations where market uncertainty is fuelled by health risks.

We also evaluate the forecast performance of including the uncertainty index in the predictive model of gold returns both for the in- and out-of-sample periods. We adopt a 75:25 data split and the rolling window approach is used to generate the forecasts. Also, the outof-sample forecast evaluation is carried out for 30-day and 60-day ahead forecasts. Since the benchmark model is nested in Eq. (1), the Clark and West (2007) (CW hereafter) test suitable for this purpose is used to determine the statistical significance in the difference 
Table 6 Estimation (predictability) results

\begin{tabular}{llll}
\hline & Full sample & Pre-COVID & COVID \\
\hline Palladium & & & \\
$\lambda^{\text {adj }}$ & $-0.0028(0.0076)[-0.3689]$ & $-0.0124(0.0795)[-0.1557]$ & $-0.0396^{* *}(0.0195)[-2.0311]$ \\
$\begin{array}{l}\text { Platinum } \\
\lambda^{\text {adj }}\end{array}$ & $-0.0361 * * *(0.0054)$ & $0.0990(0.0695)[1.4249]$ & $-0.0643 * * *(0.0193)$ \\
& {$[-6.7076]$} & & {$[-3.3281]$} \\
$\begin{array}{l}\text { Silver } \\
\lambda^{\text {adj }}\end{array}$ & $-0.0969^{* * *}(0.0087)$ & $0.5003 * * *(0.0927)[5.3061]$ & $-0.1999 * * *(0.0309)$ \\
& {$[-11.140]$} & & {$[-6.4635]$} \\
\hline
\end{tabular}

We present the predictability results for the EMV-ID only while the full results for the multivariate model are presented in the Appendix. Values in parentheses-() denote standard errors while those reported in square brackets-[] are for t-statistics

$* * *, * *, *$ Imply the rejection of the null hypothesis of no predictability at $1 \%, 5 \%, 10 \%$ levels of significance, respectively

between the forecast errors of the two nested. Since the CW test is widely used in the literature, its technical details are suppressed. We reject the hypothesis of a zero coefficient if this statistic is greater than +1.282 (for a one sided 0.10 test) or +1.645 (for a one sided 0.05 test) (see Clark and West 2007). The rejection (non-rejection) of the null hypothesis implies the superior (inferior) performance of the uncertainty-based model for gold or any other precious metal relative to the benchmark model.

In Table 5, the in-sample predictability results show that the health risk index performs well in predicting gold returns judging by the statistical significance of the $\mathrm{CW}$ test for the full-sample, and the two sub-samples for the pre-COVID and COVID samples. We seek further confirmation for the predictive role in out-of-sample forecast evaluation as described erstwhile. The ensuing results in Table 5 establish sufficient evidence for outof-sample predictive power for the new data series (over the benchmark historical average model) for the general case, that is, the full sample. Also, the same is proven for the COVID-19 period and the period of other pandemics where the estimated model appears as the preferred model over the historical average model. In the end, the forecast results prove the predictive power of the indicator for risks due to epidemics and pandemics.

\subsection{Additional results for safe haven behaviour of other precious metals}

For completeness, we test further whether other precious metals would share similar outcomes with gold. Thus, we replicate the analyses for Palladium, Platinum and Silver as argued in the introductory section for the general case of precious metals with inherent store of value properties against uncertainties (see Starr and Tran 2008; Agyei-ampomah et al. 2014; Lucey and Li 2015; Huynh 2020). In Table 6, we document the predictive role of the epidemics and pandemics indicator series for all the remaining three precious metals for the three data samples previously considered (full sample, pre-COVID and during COVID). The results follow certain consistent pattern for the three precious metals. The coefficients are negative across metals for the full sample and COVID periods, which indicates that the three metals cannot be used to hedge pandemics risks including those associated with the COVID-19 pandemic. However, for other pandemics (as shown by the analysis for the pre-COVID period), platinum and silver display hedging roles with the 
Table 7 Forecast evaluation using Clark and West test

\begin{tabular}{llll}
\hline & In-sample & Out-of-sample & \\
\cline { 3 - 4 } & & $\mathrm{h}=30$ & $\mathrm{~h}=60$ \\
\hline Palladium & & & \\
Full sample & $0.3383 * * *(0.0481)[7.0396]$ & $0.3364 * *(0.0478)[7.0332]$ & $0.3384 * * *(0.0476)[7.1040]$ \\
Pre-COVID & $0.3927 * *(0.0569)[6.9010]$ & $0.3931 * * *(0.0567)[6.9386]$ & $0.3957 * * *(0.0564)[7.0182]$ \\
Post-COVID & $2.9112 *(1.5511)[1.8769]$ & $2.8054 * *(1.3859)[2.0243]$ & $2.6173 * *(1.2514)[2.0916]$ \\
Platinum & & & \\
Full sample & $0.0736 *(0.0301)[2.4477]$ & $0.0742 * *(0.0299)[2.4785]$ & $0.0734 *(0.0298)[2.4609]$ \\
Pre-COVID & $0.0599 *(0.0331)[1.8085]$ & $0.0604 *(0.0330)[1.8326]$ & $0.0595 *(0.0328)[1.8135]$ \\
Post-COVID & $2.0805 *(1.0209)[2.0379]$ & $0.0742 * *(0.0299)[2.4785]$ & $2.1824 * *(0.8643)[2.5251]$ \\
Silver & & & \\
Full sample & $0.8496 * *(0.0971)[0.0971]$ & $0.8508 * * *(0.0966)[8.8043]$ & $0.8457 * *(0.0962)[8.7933]$ \\
Pre-COVID & $0.7921 * *(0.0965)[8.2063]$ & $0.7921 * * *(0.0962)[8.2335]$ & $0.7878 * * *(0.0957)[8.2293]$ \\
Post-COVID & $0.8739 *(2.8652)[0.3050]$ & $1.1383 *(2.5710)[0.4427]$ & $1.2966 *(2.3221)[0.5584]$ \\
\hline
\end{tabular}

The rejection of the null hypothesis implies the preference for the uncertainty-based model for gold returns, otherwise, it is not preferred to the benchmark model. The null hypothesis of a zero coefficient is rejected if this statistic is greater than +1.282 (for a one sided 0.10 test) +1.645 (for a one sided 0.05 test) and +2.00 for 0.01 test (for a one sided 0.01 test) (see Clark and West 2007). Values in parentheses-() denote standard errors while those reported in square brackets-[] are for t-statistics

$* * *, * *$, *Imply the rejection of the null hypothesis of equal forecast accuracy at $1 \%, 5 \%, 10 \%$ levels of significance, respectively

exception of palladium. These findings find root in previous works showing that the behaviour of gold may differ from those of other precious metals (Batten et al. 2010; O'Connor et al. 2015; Vigne et al. 2017).

In all, our findings point to gold (excluding the remaining three precious metals) with undeniable abilities to protect investors against health-related market risks. However, the analysis on forecasting shows that the predictive models for all the four precious metals containing health risk as the predictor outperform the baseline model. Hence, the information contained in the new index (uncertainty due to epidemics and pandemics) can be exploited to improve the in-sample and out-of-sample forecasts precious metals' returns (see evidences in Table 7 that show that the preferred model outperforms the baseline model (i.e. historical average)). Thus, for investors and financial analysts who rely on forecasts or projections when making investment decisions particularly during pandemics, the new index measuring health risk offers additional crucial information.

\section{Conclusion}

This paper explores the safety-guarantee offered by gold, amidst other precious metals (silver, platinum and palladium), against health-induced market uncertainty risks due to infectious diseases (epidemics and pandemics) with special focus on the COVID-19 pandemic. It considers the newly proposed EMV-ID dataset (Equity Market Volatility - Infectious Diseases tracker) of Baker et al. (2020) for this purpose. This represents worthy contribution to the body of literature that shows the resilience of some special classes of assets like 
gold, commodities, cryptocurrency and others to a number of risks, for instance, inflation, currency, political, and policy uncertainties. The study assesses the safe haven property of the precious metals during times of market turbulence posed by epidemics and pandemics including the COVID-19 pandemic using the Westerlund and Narayan $(2012,2015)$ estimator which incorporates endogeneity bias, conditional heteroscedasticity effect and persistence, some of which were pinned to the data. The study further probes the predictive content of the new index for measuring health risk for both the in-sample and out-ofsample forecasts of the returns of precious metals.

From the preliminary results, we show that market uncertainty measured by the EMVID data is unusually higher during COVID-19 pandemic while gold return series remains positive, on average, as theoretically expected. Also, the outcome of the forecast analysis shows that the information contained in the new index (uncertainty due to epidemics and pandemics) can be exploited to improve the in-sample and out-of-sample forecasts of precious metals' returns. The findings of hedging effectiveness show that gold is the lone precious metal with hedging powers against health risks and displays unreserved safe haven properties on average and during turbulent times defined by the COVID-19 period.

Consequently, we draw the following policy implications from our findings. First, investors seeking to minimize the risks associated with the COVID-19 pandemic are encouraged to include gold in their investment portfolio as doing so can provide cover against any loss suffered from other investments that are susceptible to the pandemic. In other words, taking a long position in the gold market and a short position in the traditional financial market during the pandemic is desirable for a profit maximizing investor. Several studies analysing the connection between the traditional financial markets (such as the stock market and foreign exchange market, among others) and the COVID-19 pandemic have reported a negative association suggesting the vulnerability of these markets to the pandemic (see on stock market, Gil-Alana and Claudio-Quiroga 2020; Salisu et al. 2020a, b, c; Liu et al. 2020; Salisu and Akanni 2020; Salisu and Sikiru 2020; Sharma 2020, among others), and on foreign exchange market, see Narayan 2020a, b; Narayan et al. 2020, among others). Second, since the information content of the pandemic improves the forecast accuracy of gold returns, financial analysts whose forecasts are often used for investment decision purposes would find this outcome useful. Third, also evident in this study is the fact that not all precious metals can provide protection against the COVID-19 pandemic and therefore investors should be wary of investing in some precious metals as they seem to behave like the traditional financial markets.

Finally, an extension of our study that offers the economic significance of the predictability results would be more insightful. This extension is expected to cover portfolio strategies where the amount of long and short positions required to minimize risks during the pandemic would be determined.

\section{Appendix}

See Table 8 . 
Table 8 Full results of the predictive model

\begin{tabular}{|c|c|c|c|}
\hline & Full sample & Pre-COVID & COVID \\
\hline \multicolumn{4}{|l|}{ Gold } \\
\hline EMV-ID & $0.0389 * * *(0.0053)[7.3710]$ & $0.1766 * * *(0.0461)[3.8348]$ & $0.0517 * * *(0.0061)[8.4583]$ \\
\hline Oil price & $-0.0120(0.0113)[-1.0577]$ & $0.0605 * * *(0.0166)[3.6365]$ & $\begin{array}{l}-0.0521 * * *(0.0083) \\
\quad[-6.2554]\end{array}$ \\
\hline Exchange rate & $\begin{array}{l}0.5200 * * *(0.0503) \\
\quad[10.3399]\end{array}$ & $\begin{array}{l}0.5378 * * *(0.0526) \\
\quad[10.2283]\end{array}$ & $\begin{array}{c}-0.3205 * * *(0.1117) \\
{[-2.8686]}\end{array}$ \\
\hline \multicolumn{4}{|l|}{ Palladium } \\
\hline EMV-ID & $-0.0028(0.0076)[-0.3689]$ & $-0.0124(0.0795)[-0.1557]$ & $\begin{array}{l}-0.0396 * *(0.0195) \\
{[-2.0311]}\end{array}$ \\
\hline Oil price & $0.0178(0.0199)[0.8966]$ & $0.0327(0.0271)[1.2038]$ & $-0.0204(0.0420)[-0.4846$ \\
\hline Exchange rate & $\begin{array}{l}1.2363 * * *(0.1003) \\
{[12.3309]}\end{array}$ & $\begin{array}{l}1.2466 * * *(0.1083) \\
\quad[11.5059]\end{array}$ & $2.0400 * * *(0.3556)[5.7362]$ \\
\hline \multicolumn{4}{|l|}{ Platinum } \\
\hline EMV-ID & $\begin{array}{c}-0.0361 * * *(0.0054) \\
{[-6.7076]}\end{array}$ & $0.0990(0.0695)$ [1.4249] & $\begin{array}{c}-0.0643 * * *(0.0193) \\
\quad[-3.3281]\end{array}$ \\
\hline Oil price & $\begin{array}{c}-0.0645 * * *(0.0161) \\
{[-3.9977]}\end{array}$ & $\begin{array}{l}-0.1109 * * *(0.0202) \\
\quad[-5.4841]\end{array}$ & $0.0670(0.0542)[1.2356]$ \\
\hline $\begin{array}{l}\text { Exchange rate } \\
\text { Silver }\end{array}$ & $0.7066 * * *(0.0765)[9.2425]$ & $0.6483(0.0803)[8.0763]$ & $0.5699(0.3543)[1.6085]$ \\
\hline EMV-ID & $\begin{array}{c}-0.0969 * * *(0.0087) \\
{[-11.140]}\end{array}$ & $0.5003 * * *(0.0927)[5.3061]$ & $\begin{array}{c}-0.1999 * * *(0.0309) \\
{[-6.4635]}\end{array}$ \\
\hline Oil price & $0.1344 * * *(0.0287)[4.6876]$ & $\begin{array}{l}0.3689 * * *(0.0316) \\
\quad[11.6900]\end{array}$ & $\begin{array}{c}-0.5942 * * *(0.0931) \\
\quad[-6.3812]\end{array}$ \\
\hline Exchange rate & $\begin{array}{l}1.7745 * * *(0.1125) \\
\quad[15.7710]\end{array}$ & $\begin{array}{l}1.4996 * * *(0.1121) \\
{[13.3795]}\end{array}$ & $3.3880 * * *(0.6543)[5.1782]$ \\
\hline
\end{tabular}

The table reports the full results for the multivariate model estimated. The EMV-ID denotes the uncertainty index due to infectious diseases. Values in parentheses-() denote standard errors while those reported in square brackets-[] are for t-statistics

$* * *, * *, *$ Imply the rejection of the null hypothesis of no predictability at $1 \%, 5 \%, 10 \%$ levels of significance, respectively

Author contributions Abdulsalam Sikiru: Writing the revised manuscript, Methodology, Formal Analysis, Results Validation, Reviewing and Editing. Afees Salisu: Conceptualization, Methodology, Formal Analysis, Software, Writing_-Original Draft, Reviewing \& Editing.

Funding No specific financial support was received to carry out the study.

Data availability The data that support the findings of this study are available on FRED Economic data of St. Louis using the https://fred.stlouisfed.org.

Code availability The codes used for analysis can be made available by the authors on request.

\section{Declarations}

Conflict of interest The author does not have any conflict of interest to declare. 


\section{References}

Adediran, I.A., Yinusa, O.D., Lakhani, K.H.: Where lies the silver lining when uncertainty hang dark clouds over the global financial markets? Resour. Policy 70, 101932 (2021)

Agyei-Ampomah, S.A.M., Gounopoulos, D., Mazouz, K.: Does gold offer a better protection against losses in sovereign debt bonds than other metals? J. Bank. Finance 40, 507-521 (2014)

Akhtaruzzaman, M., Boubaker, S., Lucey, B.M., Sensoy, A.: Is Gold a Hedge or Safe Haven Asset during COVID-19 Crisis? (2020). https://ssrn.com/abstract=3621358 or https://doi.org/10.2139/ssrn.36213 58

Areal, N., Oliveira, B., Sampaio, R.: When times get tough, gold is golden. Eur. J. Finance 21(6), 507-526 (2015)

Bai, J., Perron, P.: Computation and analysis of multiple structural change models. J. Appl. Econom. 18, 1-22 (2003)

Baker, S.R., Bloom, N., Davis, S.J.: Equity Market Volatility: Infectious Disease Tracker [INFECTDISEMVTRACK]. Retrieved from FRED, Federal Reserve Bank of St. Louis; https://fred.stlouisfed.org/ series/INFECTDISEMVTRACK, June 12, 2020

Balcilar, M., Gupta, R., Pierdzioch, C.: Does uncertainty move the gold price? New evidence from a nonparametric causality-in-quantiles test. Resour. Policy 49, 74-80 (2016)

Batten, J., Ciner, C., Lucey, B.: The macroeconomic determinants of volatility in precious metals markets. Resour. Policy 35(2), 65-71 (2010)

Batten, J.A., Ciner, C., Lucey, B.M.: On the Economic Determinants of the Gold-Inflation Relation. Resour. Policy 41, 101-108 (2014)

Baur, D.G., Lucey, B.M.: Flights and contagion-an empirical analysis of stock-bond correlations. J. Financ. Stab. 5(4), 339-352 (2009)

Baur, D.G., Lucey, B.M.: Is gold a hedge or a safe haven? An analysis of stocks, bonds and gold. Financ. Rev. 45(2), 217-229 (2010)

Baur, D.G., Mcdermott, T.K.: Is gold a safe haven? International evidence. J. Bank. Finance 34, 1886-1898 (2010)

Beckmann, J., Berger, T., Czudaj, R.: Does gold act as a hedge or a safe haven for stocks? A smooth transition approach. Econ. Model. 48, 16-24 (2015)

Beckmann, J., Berger, T., Czudaj, R.: Gold price dynamics and the role of uncertainty. Quant. Finance 19(4), 663-681 (2018)

Bialkowski, J., Bohl, M.T., Stephan, P.M., Wisniewski, T.P.: The gold price in times of crisis. Int. Rev. Financ. Anal. 41, 329-339 (2015)

Bilgin, M.H., Gozgor, G., Lau, C.K.M., Sheng, X.: The effects of uncertainty measures on the price of gold. Int. Rev. Financ. Anal. 58, 1-7 (2018)

Bouri, E., Shahzad, S.J.H., Roubaud, D., Kristoufek, L., Lucey, B.: Bitcoin, gold, and commodities as safe havens for stocks: new insight through wavelet analysis. Q. Rev. Econ. Finance (2020)

Bredin, D., Conlon, T., Potì, V.: Does gold glitter in the long-run? Gold as a hedge and safe haven across time and investment horizon. Int. Rev. Financ. Anal. 41, 320-328 (2015)

Bredin, D., Conlon, T., Poti, V.: The price of shelter-downside risk reduction with precious metals. Int. Rev. Financ. Anal. 49, 48-58 (2017)

Burggraf, T., Fendel, R., Huynh, T.L.D.: Political news and stock prices: evidence from Trump's trade war. Appl. Econ. Lett. 1-4 (2019)

Chai, G., You, D., Chen, J.: Dynamic response pattern of gold prices to economic policy uncertainty. Trans. Nonferrous Met. Soc. China 29, 2667-2676 (2019)

Clark, T.E., West, K.D.: Approximately normal tests for equal predictive accuracy in nested models. J. Econom. 138, 291-311 (2007)

Conlon, T., McGee, R.: Safe haven or risky hazard? Bitcoing during the COVID-19 bear market. Financ. Res. Lett. (2020). https://doi.org/10.1016/j.frl.2020.101607

Conlon, T., Lucey, B.M., Uddin, G.S.: Is gold a hedge against inflation? A wavelet time-scale perspective. Rev. Quant. Financ. Acc. 51(2), 317-345 (2018)

Corbet, S., Larkin, C., Lucey, B.: The contagion effects of the COVID-19 pandemic: evidence from Gold and Cryptocurrencies. Finance Res. Lett. 101554 (2020a)

Corbet, S., Hou, G., Hu, Y., Larkin, C. J., Oxley, L.: Any Port in a Storm: Cryptocurrency Safe-Havens During the COVID-19 Pandemic. SSRN 3610461 (2020b)

Dong, X., Yoon, S.: What global economic factors drive emerging Asian stock market returns? Evidence from a dynamic model averaging approach. Econ. Model. 77, 204-215 (2019)

Gao, R., Zhang, B.: How does economic policy uncertainty drive gold-stock correlations? Evidence from the UK. Appl. Econ. 48, 3081-3087 (2016) 
Gil-Alana, L.A., Claudio-Quiroga, G.: The COVID-19 impact on the Asian stock markets. Asian Econ. Lett. (2020). https://doi.org/10.46557/001c.17656

Gozgor, G., Ongan, S.: Economic policy uncertainty and tourism demand: empirical evidence from the USA. Int. J. Tour. Res. 19(1), 99-106 (2017)

Hou, K., Tang, K., Zhang, B.: Political Uncertainty and Commodity Prices. Working paper no. 2017-03025. Fisher College of Business (2017)

Huynh, D.L.: The effect of uncertainty on the precious metals market: New insights from Transfer Entropy and Neural Network VAR. Resour. Policy (2020). https://doi.org/10.1016/j.resourpol.2020.101623

Huynh, T.L.D., Burggraf, T.: If Worst Comes to Worst: Co-movement of Global Stock Markets in the USChina Trade War. SSRN 3466245 (2019)

Jain, A., Ghosh, S.: Dynamics of global oil prices, exchange rate and precious metal prices in India. Resour. Policy 38, 88-93 (2013)

Ji, Q., Zhang, D., Zhao, Y.: Searching for safe-haven assets during the COVID-19 pandemic. Int. Rev. Financ. Anal. 101526 (2020)

Jones, A.T., Sackley, W.H.: An uncertain suggestion for gold-pricing models: The effect of economic policy uncertainty on gold prices. J. Econ. Finance 40, 367-379 (2016)

Li, S., Lucey, B.M.: Reassessing the role of precious metals as safe havens-what colour is your haven and why? J. Commod. Mark. 7, 1-14 (2017)

Liu, L., Wang, E.-Z., Lee, C.-C.: Impact of the COVID-19 pandemic on the crude oil and stock markets in the US: a time-varying analysis. Energy Res. Lett. (2020). https://doi.org/10.46557/001c.13154

Lucey, B.M., Li, S.: What precious metals act as safe havens, and when? Some US evidence. Appl. Econ. Lett. 22(1), 35-45 (2015)

Lucey, B.M., Sharma, S.S., Vigne, S.A.: Gold and Inflation(s)—a time-varying relationship. Econ. Model. 67, 88-101 (2017)

Narayan, P.K.: Has COVID-19 changed exchange rate resistance to shocks? Asian Econ. Lett. (2020c). https://doi.org/10.46557/001c.17389

Narayan, P.K.: Oil price news and COVID-19-is there any connection? Energy Res. Lett. (2020a). https:// doi.org/10.46557/001c. 13176

Narayan, P.K.: Did bubble activity intensify during COVID-19? Asian Econ. Lett. (2020b). https://doi.org/ 10.46557/001c. 17654

Narayan, P.K., Liu, R.: A unit root model for trending time-series energy variables. Energy Econ. 50, 391402 (2015)

Narayan, P.K., Devpura, N., Wang, H.: Japanese currency and stock market-what happened during the COVID-19 pandemic? Econ. Anal. Policy 68, 191-198 (2020)

Nguyen, D.T., Phan, D.H.B., Ming, T.C., Nguyen, V.K.L.: An assessment of how COVID-19 changed the global equity market. Econ. Anal. Policy 69, 480-491 (2021)

O’Connor, F.A., Lucey, B.M., Batten, J.A., Baur, D.G.: The financial economics of gold-a survey. Int. Rev. Financ. Anal. 41, 186-205 (2015)

Otero, L.A., Reboredo, J.C.: The performance of precious metal mutual funds: does uncertainty matter? Int. Rev. Financ. Anal. 57, 13-22 (2018)

Peng, X.: Do precious metals act as hedges or safe havens for China's financial markets? Finance Res. Lett. (2019). https://doi.org/10.1016/j.frl.2019.101353

Qadan, M.: Risk appetite and the prices of precious metals. Resour. Policy 62, 136-153 (2019)

Qin, M., Su, C., Qi, Z., Hao, L.: Should gold be stored in chaotic eras? Econ. Res. 33(1), 224-242 (2020)

Qureshi, S., Rehman, I.U., Qureshi, F.: Does gold act as a safe haven against exchange rate fluctuations? The case of Pakistan Rupee. J. Policy Model. 40(4), 685-708 (2018)

Raza, S.A., Shah, N., Shahbaz, M.: Does economic policy uncertainty influence gold prices? Evidence from a nonparametric causality-in-quantiles approach. Resour. Policy 57, 61-68 (2018)

Reboredo, J.C., Rivera-Castro, M.A.: Can gold hedge and preserve value when the US dollar depreciates? Econ. Model. 39, 168-173 (2014)

Salisu, A.A., Adediran, I.A.: Uncertainty due to infectious diseases and energy market volatility. Energy Res. Lett 1(2), 14185 (2020). https://doi.org/10.46557/001c.14185

Salisu, A.A., Akanni, L.O.: Constructing a global fear index for COVID-19 pandemic. Emerg. Mark. Finance Trade 56(10), 2213-2230 (2020)

Salisu, A.A., Sikiru, A.A.: Pandemics and the Asia-Pacific Islamic Stocks. Asian Econ. Lett. (2020). https:// doi.org/10.46557/001c. 17413

Salisu, A.A., Raheem, I.D., Eigbiremolen, G.O.: The behaviour of U.S. stocks to financial and health risks. Int. J. Finance Econ. (2020b). https://doi.org/10.1002/ijfe.2390

Salisu, A.A., Ebuh, G.U., Usman, N.: Revisiting oil-stock nexus during COVID-19 pandemic: some preliminary results. Int. Rev. Econ. Finance 69, 280-294 (2020a) 
Salisu, A.A., Vo, X.V., Lawal, A.: Hedging oil price risk with gold during COVID-19 pandemic. Resour. Policy (2020c). https://doi.org/10.1016/j.resourpol.2020.101897

Salisu, A.A., Raheem, I.D., Vo, X.V.: Assessing the safe haven property of the gold market during COVID19 pandemic. Int. Rev. Financ. Anal. 74, 101666 (2021)

Sharma, S.S.: A note on the Asian market volatility during the COVID-19 pandemic. Asian Econ. Lett. (2020). https://doi.org/10.46557/001c.17661

Starr, M., Tran, K.: Determinants of the physical demand for gold: evidence from panel data. World Econ. 31, 416-436 (2008)

Vigne, S.A., Lucey, B.M., O'Connor, F.A.: The financial economics of white precious metals-a survey. Int. Rev. Financ. Anal. (2017). https://doi.org/10.1016/j.irfa.2017.04.006

Westerlund, J., Narayan, P.K.: Does the choice of estimator matter when forecasting returns? J. Bank. Finance 36, 2632-2640 (2012)

Westerlund, J., Narayan, P.K.: Testing for predictability in conditionally hetoroscedasticity stock returns. J. Financ. Econom. 13, 342-375 (2015)

Zhang, D., Hu, M., Ji, Q.: Financial markets under the global pandemic of COVID-19. Finance Res. Lett. (2020). https://doi.org/10.1016/j.frl.2020.101528

Publisher's Note Springer Nature remains neutral with regard to jurisdictional claims in published maps and institutional affiliations. 